\title{
Lung Cancer Survival with Current Therapies and New Targeted Treatments: A Comprehensive Update from the Srinagarind Hospital-Based Cancer Registry from (2013 to 2017)
}

\author{
Wachiraporn Musika ${ }^{1}$, Supot Kamsa-Ard ${ }^{2,3 *}$, Chananya Jirapornkul ${ }^{2,3}$, \\ Chalongpon Santong ${ }^{4}$, Anakapong Phunmanee ${ }^{5}$
}

\begin{abstract}
Background: Lung cancer (LC) is a common malignancy and leading cause of cancer death worldwide and in Thailand. An update on LC survival factors after diagnosis at Srinagarind Hospital is needed. Methods: We conducted a retrospective cohort study, and the data were sourced from the Srinagarind Hospital-Based Cancer Registry. All LC cases were diagnosed between January 1, 2013, and December 31, 2017, and followed up until November 30, 2019. Cases of LC (ICD-O-3) numbered 2,149, but only those with coding C34.0-C34.9 were included. The survival rate was estimated using Kaplan-Meier, while the Log-rank test was used to estimate survival. Hazard ratios (HRs) and 95\% confidence intervals (CIs) were estimated using Cox proportional hazard regression models. Results: The 2,149 patients had a total follow-up of 269.6 person-years. Overall, 1,867 patients died during the study, for a corresponding case-fatality mortality rate of 86.0 per 100 person-years. The respective 1 -, 3 -, and 5-year survival rate was $31.2 \%(95 \%$ CI; 29.21 to $33.15 \%), 12.9 \%$ (95\%CI: 11.49 to 14.45$)$, and $10.2 \%$ (95\% CI: 8.74 to 11.70$)$. After patient diagnosis, the median survival time was 0.46 years (5.51 months) (95\% CI: 0.42 to 0.50$)$. Targeted therapy was associated with longer survival than non-targeted therapy ( $\mathrm{p}$-value $<0.001$ ). After adjusting for sex, TNM stage, and histologic type, multivariable analysis of the entire cohort identified chemotherapy as an independent predictor of improved survival (adjusted $\mathrm{HR}=0.48 ; 95 \% \mathrm{CI}: 0.42$ to $0.55 ; \mathrm{P}<0.001$ ), and that sex, TNM stage, and histologic type were associated with survival. Conclusion: The study confirmed that sex, stage of disease, histology, and chemotherapy are associated with survival of LC. Primary prevention and screening for early detection improve survival. Further investigations into factors affecting survival of LC in Northeast Thailand should focus on targeted therapy.
\end{abstract}

Keywords: Lung cancer- survival- cancer registry- targeted therapy

Asian Pac J Cancer Prev, 22 (8), 2501-2507

\section{Introduction}

Lung cancer (LC) is a malignant tumor with the highest global morbidity and mortality of all cancers. In 2018, the number of new cases was $2,093,876$ ( $11.6 \%$ of all cancers), while the number of deaths was $1,761,007$ (18.4\% of all cancers) among both sexes for all ages (Bray et al., 2017). The respective age-standardized rate (ASR) for LC in males and females is 31.5 and 14.6 per 100,000 . The respective age-standardized incidence and mortality rate for both sexes is 22.5 and 18.6 per 100,000 (International Agency for Research on Cancer, 2019).

For Thais, the ASR for LC is between 20.6 and 27.1 per 100,000 in males and between 9.3 and 11.9 per 100,000 in females. In Khon Kaen province, Thailand, the ASR is between 18.0 and 21.1 per 100,000 in males and between 5.9 and 7.6 per 100,000 in females. The most common histological type is non-small cell lung cancer (NSCLC) $(90.0 \%)$, followed by small cell lung cancer (SCLC) (10.0\%) (Sriplung et al., 2003; Khuhaprema et al., 2007; Khuhaprema et al., 2010; Khuhaprema et al., 2012).

The incidence trend for LC in Khon Kaen province, Thailand, has modestly increased over the last 20 years. By 2030, the incidence rate is predicted to increase among females but to decline among males (Santong et al., 2018). Prevention is a long-term strategy, and not all cancers can be prevented (Schottenfeld and Fraumeni, 2006); nevertheless, implementation of national and regional preventative programming has been uneven. In order to reduce LC mortality, a reduction of LC incidence and an

${ }^{1}$ Bueng Khong Long Hospital, Bueng Khong Long District, Bueng Kan Province, Thailand. ${ }^{2}$ Department of Epidemiology and Biostatistics, Faculty of Public Health, Khon Kaen University, Khon Kaen, Thailand. ${ }^{3}$ ASEAN Cancer Epidemiology and Prevention Research Group, Khon Kaen University, Khon Kaen, Thailand. ${ }^{4}$ Cancer Unit, Srinagarind Hospital, Faculty of Medicine, Khon Kaen University, Khon Kaen, Thailand. ${ }^{5}$ Department of Medicine, Faculty of Medicine, Khon Kaen University, Khon Kaen, Thailand. *For Correspondence: supot@kku.ac.th 
improvement of LC survival are essential (Allemani et al., 2018). The first-ever population-based cancer survival data (1985-1992) for Khon Kaen, Thailand, were published in 1995. The study revealed that the most common cancers in the province were liver (5-year relative survival rate $9.2 \%)$, cervix $(60.1 \%)$, lung $(15.4 \%)$, breast $(48.1 \%)$, and large bowel (41.9\%) (Sriamporn et al., 1995). A later study on Cancer Survival in Khon Kaen, Thailand, revealed that the 5-year survival between 1993 and 1997 was highest for localized disease, followed by regional and distant metastatic categories. Trends in the 5-year relative survival between 1993 and 1997 vs. 1985 and 1992 showed a marked increase for cancers of the rectum, breast, ovary, Hodgkin and non-Hodgkin lymphomas, and a decrease for cancers of the lip and larynx (Suwanrungruang et al., 2011). Previous studies showed the prognostic factors in non-small cell LC patients include stage of disease, performance status (León-Atance et al., 2011), weight loss, male vs. female, age, smoking status, smoking history, quality of life, marital status, diagnosed with depression, and genetic mutations (Jazieh et al., 2000; Brundage et al., 2002).

The prognostic factors and survival rate for LC have not been updated recently for the tertiary hospitals in northeastern Thailand where cancer patients are treated. The current research thus aimed to determine the factors affecting the survival of LC patients after diagnosis at Srinagarind Hospital.

\section{Materials and Methods}

\section{Cancer Registries and Case Ascertainment}

Khon Kean Cancer Registry, KKCR

The Khon Kaen Cancer Registry (KKCR) was established in 1984 at the Faculty of Medicine and Srinagarind Hospital, Khon Kaen University, Khon Kaen, Thailand. It comprises both hospital and population-based registrations. The KKCR contains data on 1.7 million patients comprising all cancer sites as per the International Agency for Research on Cancer (IARC) guidelines (Esteban et al., 1995).

\section{Case definitions}

The database was retrieved for all patients with LC tumors treated at Srinagarind Hospital, Faculty of Medicine, Khon Kaen University between January 1, 2013, and December 31, 2017. Diagnoses were obtained using the International Classification of Diseases for Oncology, 3rd edition (ICD-O-3). LC is an ICD-O-3 diagnosis and only includes coding C34.0-C34.9 (World Health Organization, 2013).

\section{Statistical methods}

Descriptive epidemiology of study patients

The characteristics of the patients were summarized using descriptive statistics. Means and standard deviations, medians, and their ranges (minima and maxima) were used for continuous variables, and frequency counts and percentages were used for categorical variables.

Survival analyses

Survival analyses excluded cases if their basis of diagnosis was Death Certificate Only (DCO) or unknown, if they did not contain any follow-up information, or had an unknown vital status. Survival was determined by calculating the follow-up time from diagnosis to each patient's last known vital status. The status was obtained by linking records between the Mortality Registry of Thailand (National Health Office, 2017) and the National Statistical Office (National Statistical Office Thailand, 2017, updated to December 31, 2016).

The observed survival (OS) analysis was estimated using the Kaplan-Meier survival curve, and the logrank test was used for between-group comparisons. Multivariable analysis was performed using Cox proportional hazards regression (Kleinbaum and Klein, 2005). All test statistics were two-sided, and a p-value of $<0.05$ was considered statistically significant.

\section{Data processing}

Data were recorded using the CanReg 5 software provided by the International Association of Cancer Registries (IARC) (IARC, 2019). The verification was performed with necessary corrections, including logic, range, and internal consistency, which were checked using statistical software. All analyses were performed using Stata release 10.0 (StataCorp LLC, College Station, TX, USA). (Stata Corp, 2007)

\section{Ethical considerations}

This project was reviewed and approved by the Human Research and Ethics Committee of Khon Kaen University (HE631214).

\section{Results}

\section{Descriptive epidemiology and Data quality}

Between 2013 and 2017, 2,149 cases of LC were recorded in the Srinagarind Hospital-Based Cancer Registry database. Male LC patients outnumbered female LC patients. The age at diagnosis trended to be late middleaged (mean, 62.4 years; standard deviation, 11.3; median, 63.0 years; Min: Max; 20: 91). Most were "married" $(n=2,041 ; 95.1 \%)$. As for the year of diagnosis, the most numerous was in $2014(\mathrm{n}=497 ; 23.1 \%)$, while the least was in 2017 ( $\mathrm{n}=364 ; 16.9 \%)$.

The basis of diagnosis was endoscopic and radiologic evidence vs. morphological verification $(n=1,534$; $71.4 \%$ ) (i.e., based on either cytological or histological examination of tissue from the primary site, \%MV). Based on the subtype of cancer, the highest was in the upper lobe $(\mathrm{n}=818 ; 38.1 \%)$, while the lowest was overlapping lesions of the lung $(n=35 ; 1.6 \%)$. The most common histological grading was adenocarcinoma $(n=930 ; 43.3 \%)$, while the highest was "unknown grading" $(\mathrm{n}=1,815 ; 84.5 \%)$.

The most common stage of diseases were 'Stage IV' $(n=1,150 ; 53.5 \%$ and "Stage I" $(n=35 ; 1.6 \%)$. A histological grading was commonly lacking (males; $\mathrm{n}=9,199,97.6 \%$; females; $\mathrm{n}=4,282,97.9 \%$ ). Tumour laterality was often unknown or undefined $(n=885$, $41.2 \%)$. Metastatic lung cancer was bone metastasis $(\mathrm{n}=288,13.4 \%)$. For treatment, only targeted therapy was offered to 37 patients $(1.7 \%)$ while supportive care was 
Table 1. Characteristics of Study Participants Diagnosed at Srinagarind Hospital between 2013 and 2017

\begin{tabular}{|c|c|c|}
\hline Characteristic & $\begin{array}{c}\text { Number } \\
(\mathrm{n}=2,149)\end{array}$ & $\begin{array}{c}\text { Percentage } \\
(\%)\end{array}$ \\
\hline \multicolumn{3}{|l|}{ Sex } \\
\hline Male & 1,420 & 66.1 \\
\hline Female & 729 & 33.9 \\
\hline \multicolumn{3}{|l|}{ Age at diagnosis (years) } \\
\hline $20-29$ & 14 & 0.7 \\
\hline $30-39$ & 47 & 2.2 \\
\hline $40-49$ & 205 & 9.5 \\
\hline $50-59$ & 571 & 26.6 \\
\hline $60-69$ & 718 & 33.4 \\
\hline $70-79$ & 485 & 22.6 \\
\hline$>80$ & 109 & 5.1 \\
\hline Mean (standard deviation) & $62.4(11.3)$ & \\
\hline Median (minimum: maximum) & 63.0 & $0: 91)$ \\
\hline \multicolumn{3}{|l|}{ Marital status } \\
\hline Single & 59 & 2.8 \\
\hline Married & 2041 & 95.1 \\
\hline Monk & 42 & 2 \\
\hline Not specify & 7 & 0.3 \\
\hline \multicolumn{3}{|l|}{ Year of Diagnosis } \\
\hline 2013 & 489 & 22.8 \\
\hline 2014 & 497 & 23.1 \\
\hline 2015 & 385 & 17.9 \\
\hline 2016 & 414 & 19.3 \\
\hline 2017 & 364 & 16.9 \\
\hline \multicolumn{3}{|l|}{ Basis of diagnosis } \\
\hline History \& Physical exam & 5 & 0.2 \\
\hline Ultrasound (Endoscopy \& Radiology) & 602 & 28 \\
\hline Surgery \& Autopsy (no histol.) & 6 & 0.3 \\
\hline Specific Biochem/ Immuno. test & 2 & 0.1 \\
\hline Cytology or Hematology & 195 & 9.1 \\
\hline Histology of Metastasis & 24 & 1.1 \\
\hline Histology of Primary & 1315 & 61.2 \\
\hline \multicolumn{3}{|l|}{ Subtype } \\
\hline Main bronchus & 51 & 2.4 \\
\hline Upper lobe, lung & 818 & 38.1 \\
\hline Middle lobe, lung & 82 & 3.8 \\
\hline Lower lobe, lung & 466 & 21.7 \\
\hline Overlapping lesion of lung & 35 & 1.6 \\
\hline Lung, NOS & 697 & 32.4 \\
\hline \multicolumn{3}{|l|}{ Histology } \\
\hline Squamous cell carcinoma & 156 & 7.3 \\
\hline Adenocarcinoma & 930 & 43.3 \\
\hline Small cell carcinoma & 43 & 2 \\
\hline Large cell carcinoma & 160 & 7.5 \\
\hline Other specified carcinoma & 34 & 1.6 \\
\hline Sarcoma & 8 & 0.4 \\
\hline Non-small cell carcinoma & 128 & 6 \\
\hline Other specified malignant neoplasm & 9 & 0.4 \\
\hline Unspecified malignant neoplasm & 681 & 31.7 \\
\hline
\end{tabular}

Table 1. Continued

\begin{tabular}{|c|c|c|}
\hline Characteristic & $\begin{array}{c}\text { Number } \\
(\mathrm{n}=2,149)\end{array}$ & $\begin{array}{c}\text { Percentage } \\
\quad(\%)\end{array}$ \\
\hline \multicolumn{3}{|l|}{ Histology grading } \\
\hline Well differentiated & 50 & 2.3 \\
\hline Moderately differentiated & 56 & 2.6 \\
\hline Poorly differentiated & 196 & 9.1 \\
\hline Undifferentiated & 32 & 1.5 \\
\hline Not known & 1815 & 84.5 \\
\hline \multicolumn{3}{|l|}{ Laterality } \\
\hline Right & 689 & 32.1 \\
\hline Left & 541 & 25.2 \\
\hline Bilateral & 34 & 1.6 \\
\hline Unknown & 885 & 41.2 \\
\hline \multicolumn{3}{|l|}{ Stage of disease } \\
\hline Stage I & 35 & 1.6 \\
\hline Stage II & 49 & 2.3 \\
\hline Stage III & 356 & 16.6 \\
\hline Stage IV & 1150 & 53.5 \\
\hline Unknown & 559 & 26 \\
\hline \multicolumn{3}{|l|}{ Metastasis } \\
\hline Lymp node metastasis & 70 & 3.3 \\
\hline Bone metastasis & 288 & 13.4 \\
\hline Liver metastasis & 79 & 3.7 \\
\hline \multicolumn{3}{|l|}{ Treatment } \\
\hline Surgery & 140 & 6.5 \\
\hline Radiation & 393 & 18.3 \\
\hline Chemotherapy & 669 & 31.1 \\
\hline Targeted therapy & 37 & 1.7 \\
\hline Supportive care & 910 & 42.4 \\
\hline
\end{tabular}

offered to $1,198(55.8 \%)$ (Table 1$)$.

\section{Survival rate of $L C$ after diagnosis}

Mortality rate and Median survival time

The 2,149 patients had a total follow-up of 269.6 person-years. Overall, 1,867 patients died during the study, corresponding to a mortality rate (case-fatality) of 86.0 per 100 person-years. The respective 1-, 3-, and 5-year survival rate was $31.2 \%$ (95\% confidence interval; 29.21 to $33.15 \%), 12.9 \%$ (95\%CI: 11.49 to 14.45 ), and $10.2 \%$ ( $95 \% \mathrm{CI}: 8.74$ to 11.70 ). After diagnosis, the median survival time was 0.46 years $(5.51$ months) $(95 \% \mathrm{CI}$ : $0.42-0.50)$.

Based on the type of cancer, the respective median overall survival (OS) and 3-year OS rates for patients with small-cell lung cancer (SCLC) and non-small cell lung cancer (NSCLC) was 0.58 year (95\%CI: 0.39 - 0.76 ) and $11.6 \%(95 \% \mathrm{CI}$ : 4.26 to 23.06$)$ vs. 0.60 years $(95 \% \mathrm{CI}$ : 0.53 to 0.66 ) and $15.1 \%$ (95\%CI: 13.21 to 17.19$)$. As for SCLC, the respective 1-year OS rate for patients treated with chemotherapy vs. non-chemotherapy was not significantly different. Meanwhile, NSCLC patients treated with chemotherapy over non-chemotherapy were associated with longer survival (Table 2). 
Table 2. The 1-, 3-, 5-Year Survival Rate between 2013 and 2017 for LC after Diagnosis, by Cell Type and Chemotherapy Treatment at Srinagarind Hospital

\begin{tabular}{|c|c|c|c|c|c|}
\hline Variable & Number & Median time $(95 \% \mathrm{CI})$ & $\begin{array}{c}1 \text {-year } \\
\text { Survival rate }(95 \% \mathrm{CI})\end{array}$ & $\begin{array}{c}\text { 3-year } \\
\text { Survival rate }(95 \% \mathrm{CI})\end{array}$ & $\begin{array}{c}\text { 5-year } \\
\text { Survival rate }(95 \% \mathrm{CI})\end{array}$ \\
\hline \multicolumn{6}{|l|}{ Cell type } \\
\hline SCLC & 43 & $0.58(0.39-0.76)$ & $27.9(15.57-41.65)$ & $11.63(4.26-23.06)$ & NA \\
\hline NSCLC & 1374 & $0.60(0.53-0.66)$ & $37.8(35.20-40.34)$ & $15.14(13.21-17.19)$ & $11.9(10.01-14.01)$ \\
\hline \multicolumn{6}{|c|}{ SCLC with Chemotherapy } \\
\hline Yes & 22 & $0.60(0.32-0.88)$ & $27.3(11.12-46.37)$ & NA & NA \\
\hline No & 21 & $0.28(0.03-0.53)$ & $28.6(11.66-48.18)$ & $14.3(3.57-32.12)$ & NA \\
\hline \multicolumn{6}{|c|}{ NSCLC with Chemotherapy } \\
\hline Yes & 592 & $1.07(0.97-1.17)$ & $53.5(49.35-57.40)$ & $17.9(14.75-21.28)$ & $11.8(8.72-15.34)$ \\
\hline No & 782 & $0.33(0.30-0.37)$ & $25.8(22.79-28.96)$ & $13.1(10.78-15.68)$ & $11.9(9.52-14.46)$ \\
\hline
\end{tabular}

SCLC, small cell lung cancer; NSCLC, non-small cell lung cancer; NA,Not applicable

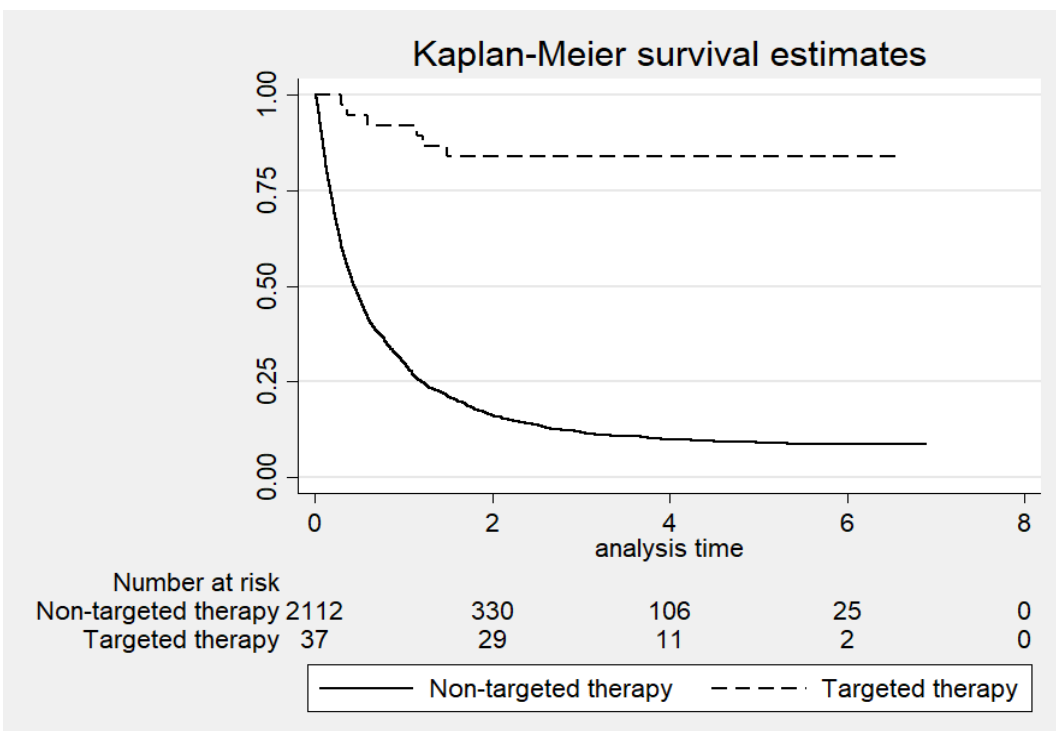

Figure 1. Overall Survival Based on Treatment of Patients (Targeted Therapy and Non-Targeted Therapy)

Effect of targeted therapy on survival

Treatment of patients with targeted over against non-targeted therapy was associated with longer survival ( $\mathrm{p}$-value $<0.001$ ). The respective 1-, 3-, and

Table 3. Multivariable Analysis between 2013 and 2017 for Overall Survival of the Entire LC Cohort after Diagnosis at Srinagarind Hospital

\begin{tabular}{|c|c|c|c|}
\hline Variable & Crude HR $(95 \% \mathrm{CI})$ & Adjusted HR $(95 \% \mathrm{CI})$ & p-value ${ }^{1}$ \\
\hline 1. Sex & & & $<0.001$ \\
\hline Male & 1 & 1 & \\
\hline Female & $0.74(0.67$ to 0.82$)$ & $0.78(0.68$ to 0.89$)$ & \\
\hline 2. TNM stage & & & $<0.001$ \\
\hline Stage I and II & 1 & 1 & \\
\hline Stage III & $3.76(2.64$ to 5.37$)$ & 6.35 (4.05 to 9.95$)$ & \\
\hline Stage IV & $5.66(4.01$ to 7.98$)$ & $8.32(5.36$ to 12.90$)$ & \\
\hline 3. Histologic type & & & $<0.001$ \\
\hline Squamous cell carcinoma & 1 & 1 & \\
\hline Adenocarcinoma & $0.76(0.63$ to 0.91$)$ & $0.78(0.63$ to 0.96$)$ & \\
\hline Small cell carcinoma & $0.98(0.69$ to 1.41$)$ & $0.79(0.50$ to 1.22$)$ & \\
\hline Large cell carcinoma & $1.08(0.88$ to 1.32$)$ & $1.01(0.80$ to 1.27$)$ & \\
\hline 4. Chemotherapy & & & $<0.001$ \\
\hline No & 1 & 1 & \\
\hline Yes & $0.55(0.49-0.60)$ & $0.48(0.42-0.55)$ & \\
\hline
\end{tabular}

'p-value from partial likelihood ratio test, Adjusted HR, adjusting for Sex;TNM stage, Histologic type, and Chemotherapy 
5-year OS rate for patients treated with targeted therapy vs. non-targeted therapy was $91.9 \%(95 \% \mathrm{CI}: 76.93$ to 97.31$)$, 83.8\% (95\%CI: 67.42 to 92.37 ), and $83.8 \%$ (95\%CI: 67.42 to 92.37$)$. Meanwhile, the respective 1-, 3-, and 5-year OS rate for patients receiving non-targeted therapy was 30.1\% (95\% $\mathrm{CI}$ : 28.14 to 32.07$), 11.8 \%$ (95\% $\mathrm{CI}: 10.38$ to 13.25 ), and $9.0 \%$ (95\% CI: 7.69 to 10.52$)$ (Figure 1).

\section{Survival and multivariable Cox regression analyses}

After adjusting for sex, TNM stage, and histologic type, multivariable analysis of the entire cohort identified chemotherapy as an independent predictor of improved survival (adjusted $\mathrm{HR}=0.48$; $95 \% \mathrm{CI}$ : 0.42 to $0.55 ; \mathrm{P}<0.001$ ), and that sex, TNM stage, and histologic type were associated with survival (Table 3).

\section{Discussion}

The current study investigated the factors affecting the survival of LC patients after diagnosis at Srinagarind Hospital between 2013 and 2017. We describe these issues in detail for each topic.

\section{Overall Survival of LC patients}

The current study showed that the respective 1-, 3-, and 5-year survival rate was 31.2\% (95\% CI: 29.21 to $33.15 \%$ ), $12.9 \%$ (95\%CI: 11.49 to 14.45$)$, and $10.2 \%$ (95\%CI: 8.74 to 11.70$)$. As for the five-year net survival (\%) estimates, the survival rate for LC from CONCORD was $10.2 \%$. The rate is below $10.0 \%$ in Thailand, Brazil, Bulgaria, and India (Allemani et al., 2018). The population-based data from the SEER registries in the USA shows that the 5-year relative survival for LC was $18.4 \%$ between 2005 and 2011, compared to $12.2 \%$ between 1975 and 1977 when SEER record-keeping began (SEER, 2015 ).

\section{Survival of LC by targeted therapy}

Despite some improvement in survival among patients treated with targeted therapies, LC remains one of the most fatal cancers. Based on available data, the current study showed that the respective 1-, 3-, and 5-year survival rate between targeted therapy and non-targeted therapy was 91.9\% (95\% CI: 76.93 to 97.31 vs. $30.1 \%$ (95\% CI: 28.14 to $32.07 \%$ ), $83.8 \%$ (95\% CI: 67.42 to 92.37$)$ vs. $11.8 \%$ (95\% CI: 10.37 to $13.25 \%$ ), and $83.8 \%$ (95\% CI: 67.42 to 92.37$)$ vs. $9.0 \%$ (95\% CI: 7.69 to $10.52 \%)$. The result is consistent with previous studies. Survival outcomes in patients with advanced non-small-cell lung cancer - treated with erlotinib - expanded access to the program data from Belgium (the TRUST study). Overall the respective survival rates at 1,2 , and 3 years was $26.4 \%, 10.9 \%$, and $6.4 \%$ (Van Meerbeeck et al., 2014). Survival of patients with advanced NSCLC treated with first-generation EGFR-TKIs at a cancer hospital in Thailand (between 2011 and 2016). The respective overall observed survival rates of patients receiving EGFR-TKIs as first-line or maintenance $(\mathrm{n}=18)$, second-line $(\mathrm{n}=18)$, and third-line or more ( $\mathrm{n}=14)$ was $15.9 \%$ (95\%CI: 10.26 to 21.46$), 10.9 \%$ (95\%CI: 0.00 to 28.29 ), and $20.2 \%$ (95\%CI: 6.26 to 34.21 ) (Sukauichai et al., 2018 ).

The respective 1- and 2-year observed survival rate of patients receiving Gefitinib was $85.0 \%$ and $57.9 \%$. For patients receiving carboplatin-paclitaxel for chemo-naïve non-small cell lung cancer with sensitive EGFR gene mutations, the respective 1- and 2-year survival NEJ002 (CBDCA/PTX) was $86.8 \%$ and $53.7 \%$ (Inoue et al., 2013).

\section{Survival factors of LC patients}

Sex

In Khon Kaen, Thailand, over the last 20 years, the trend incidence for LC has increased for both sexes. (Santong et al., 2018) Male/female is the one factor that may influence survival. Previous studies have reported that for most cancers being female provides a survival benefit over being male (Micheli et al., 2009; Cook et al., 2011), although females have a higher risk of death from bladder cancer (Zaitsu et al., 2015).

The current statistical work-up shows that male/female is a significant risk factor for LC patient survival. After adjusting all the variables in the model, the mortality risk of being female was 0.78 -fold compared to male patients (adjusted HR $=0.78$, 95\%CI: 0.68 to 0.89 ). The result is consistent with previous studies in the USA, confirming a female survival benefit over male for LC irrespective of histologic type. [30] Since then, other studies on male vs. female difference vis-à-vis LC survival have confirmed the trend (Sagerup et al., 2011; Li et al., 2019).

A similar survival benefit trend accrued to females after adjusting for years since cessation and smoking dose. The hazard ratio (HR) for LC mortality-comparing the association with smoking in women to that in men was 0.90 (adjusted HR $=0.90,95 \% \mathrm{CI}$ : 0.80 to 0.90 ) for current smokers and 0.9 (adjusted $\mathrm{HR}=0.90,95 \% \mathrm{CI}$ : 0.90 to 1.00 ) for former smokers (Freedman et al., 2008).

\section{TNM stage}

The current study shows that the 'stage of disease' is a significant risk factor for LC patient survival. After adjusting for all variables in the model, 'stage of disease' confirmed a significant risk factor of patient survival. Stage IV was associated with an 8.32-fold mortality risk compared to stages I and II (adjusted $\mathrm{HR}=8.32$; 95\%CI: 5.36 to 12.90 ), and stage III had a 6.35 -fold mortality risk compared to stages I and II (adjusted $\mathrm{HR}=6.35$; 95\%CI: 4.05 to 9.95$)$.

The results agree with a previous study wherein, compared to Stage 1, the respective mortality risk of Stage IIIB/IV, Stage IIIA, and Stage II was 5.34-fold (adjusted HR=5.34; 95\%CI: 4.95 to 5.76 ), 2.71-fold (adjusted HR=2.71; 95\%CI: 2.49 to 2.95 ), and 1.80-fold (adjusted HR=1.80; 95\%CI: 1.65 to 1.97 ) (Sculier et al., 2008). In contrast, pulmonary large cell carcinoma is an infrequent neoplasm with a poor prognosis for which 'stage of disease' had a weak association with increased mortality risk. In that study, compared to stage I, the respective increased mortality risk of Stage II, III, and IV was 1.28 -fold (adjusted HR=1.28; 95\% CI: 1.09 to 1.51 ), 1.82 (adjusted $\mathrm{HR}=1.82 ; 95 \% \mathrm{CI}: 1.59$ to 2.10 ), and 3.45 (adjusted HR=3.45; 95\% CI: 3.01 to 4.02) (Xiaochuan et al., 2020). 


\section{Histologic type}

The current study showed that histology type was not a significant risk factor for LC survival. Compared to squamous cell carcinoma, the respective associated mortality risk for adenocarcinoma, small cell carcinoma, large cell carcinoma was 0.78 -fold (adjusted $\mathrm{HR}=0.78$; 95\% CI: 0.63 to 0.96 ), 0.79 -fold (adjusted HR $=0.79 ; 95 \%$ CI: 0.50 to 1.22 ), and 1.01 -fold (adjusted HR $=1.01 ; 95 \%$ CI: 0.80 to 1.27$)$. Compared to squamous cell carcinoma, the respective associated.

Consistent with a previous study, adenocarcinoma and large cell carcinoma were associated with a 0.97 -fold (adjusted $\mathrm{HR}=0.97 ; 95 \% \mathrm{CI}: 0.68$ to 1.37 ) and a 1.01 -fold (adjusted HR $=0.01$; 95\%CI: 0.61 to 1.78 ] mortality risk compared to squamous cell carcinoma (Srisam-ang et al., 2005).

For mortality risk for NSCLC, adenocarcinoma and large cell was 0.96 -fold (adjusted $\mathrm{HR}=0.96$; 95\% CI: 0.83 to 1.11 ), 0.95 (adjusted $\mathrm{HR}=0.95,95 \% \mathrm{CI}: 0.65$ to 1.39 ) (Brzezniak et al., 2015).

\section{Chemotherapy}

The current study showed that chemotherapy afforded a significant advantaged vis-à-vis LC survival. After adjusting for all variables in the model, patients undergoing chemotherapy had improved survival. Chemotherapy was associated with a 0.48 -fold mortality risk compared to non-chemotherapy (adjusted $\mathrm{HR}=0.48$; 95\% CI: 0.42 to 0.55 ). Our finding is consistent with prior studies. Chemotherapy alone was associated with a 0.55 -fold mortality risk compared to no-treatment (adjusted HR=0.55; 95\%CI: 0.54 to 0.56 ) (Lou et al., 2018). For advanced non-small cell lung cancer, chemotherapy alone was associated with a 0.38 -fold mortality risk compared to no-treatment (adjusted $\mathrm{HR}=0.38 ; 95 \% \mathrm{CI}: 0.37$ to 0.39 ) and chemotherapy and surgery a 0.22 -fold mortality risk compared to no-treatment (adjusted HR $=0.22 ; 95 \% \mathrm{CI}$ : 0.20 to 0.24 ) (David et al., 2016).

\section{Advantages and Disadvantages of the study}

To our knowledge, the current study is the most up-todate examination of LC survival factors post-diagnosis between 2013 and 2017, according to the Srinagarind Hospital-Based Cancer Registry. Based on available data, targeted therapy significantly improved OS in LC patients of all ages, all cells types (NSCLC and SCLC), but further confirmatory research using extensive prospective clinical trials is needed. Novel targeted systemic therapies and the appropriate selection of LC patient treatments based on tumor molecular phenotypes and histologies should also be reviewed. The limitations of our study are the relatively small number of patients receiving targeted therapy.

In conclusion, the study confirmed that sex, stage of disease, histology, and chemotherapy are related to the survival of lung cancer patients. Primary prevention and screening for early detection are thus needed to improve survival. Factors affecting lung cancer survival in northeastern Thailand should focus on targeted therapy in any further investigations.

\section{Author Contribution Statement}

WM is a principal investigator and provided project management supervision. SK and CJ provided advice about the study design and statistical analyses. CS provided and supervised the interviewers, and assisted in assessing data quality. AP is a physician and operated on patients with apparent Lung cancer and assisted in the final diagnoses of the cases. SK was involved in exploratory analysis and data quality.

\section{Acknowledgements}

The authors thank (a) the KKU Cancer Unit staff for data collection and management, and (b) Mr. Bryan Roderick Hamman - under the aegis of the Publication Clinic, Khon Kaen University-for assistance with the English-language presentation of the manuscript.

\section{Statement conflict of interest}

The authors declare that they have no conflicts of interest.

\section{References}

Allemani C, Matsuda T, Di Carlo V, et al (2018). Global surveillance of trends in cancer survival 2000-14 (CONCORD-3): analysis of individual records for 37513025 patients diagnosed with one of 18 cancers from 322 population-based registries in 71 countries. Lancet, 391, 1023-75.

Bray F, Ferlay J, Soerjomataram I, et al (2018). Global cancer statistics 2018: GLOBOCAN estimates of incidence and mortality worldwide for 36 cancers in 185 countries. $C A$ Cancer J Clin, 68, 394-424.

Brundage MD, Davies D, Mackillop WJ (2002). Prognostic factors in non-small cell lung cancer: a decade of progress. Chest, 122, 1037-57.

Brzezniak C, Satram-Hoang S, Goertz HP, et al (2015). Survival and racial differences of non-small cell lung cancer in the United States Military. J Gen Intern Med, 30, 1406-12.

Cook MB, McGlynn KA, Devesa SS, Freedman ND, Anderson WF (2011). Sex disparities in cancer mortality and survival. Cancer Epidemiol Biomarkers Prev, 20, 1629-37.

David EA, Canter RJ, Chen Y, Cooke DT, Cress RD (2016). Surgical management of advanced non-small cell lung cancer is decreasing but is associated with improved survival. Ann Thorac Surg, 102, 1101-9.

Esteban D, Whelan S, Laudico A, Parkin DM (1995). Manual for Cancer Registry Personnel. Lyon: International Agency for Research on Cancer and International Association of Cancer Registries (IARC Technical Reports, No. 10). Available: https:/www.iarc.fr/en/publications/pdfs-online/treport-pub/ treport-pub10/index.php, Accessed 12 March 2018.

Ferguson MK, Skosey C, Hoffman PC, et al (1990). Sex-associated differences in presentation and survival in patients with lung cancer. J Clin Oncol, 8, 1402-7.

Freedman ND, Leitzmann MF, Hollenbeck AR, Schatzkin A, Abnet CC (2008). Cigarette smoking and subsequent risk of lung cancer in men and women: analysis of a prospective cohort study. Lancet Oncol, 9, 649-56.

Inoue A, Kobayashi K, Maemondo M, et al (2013). Updated overall survival results from a randomized phase III trial comparing gefitinib with carboplatin-paclitaxel for chemo-naïve non-small cell lung cancer with sensitive EGFR 
gene mutations (NEJ002). Ann Oncol, 24, 54-9.

International Agency for Research on Cancer (IARC), (2018) .Cancer Fact Sheets. Trachea, bronchus and lung (C33-34). Available: https:/gco.iarc.fr/today/data/factsheets/cancers /15-Lung-fact-sheet.pdf, Accessed 25 November 2019.

International Association of Cancer Registries. IACR, CanReg5. Available: http://www.iacr.com.fr/, Accessed 25 November 2017.

Jazieh AR, Hussain M, Howington JA, et al (2000). Prognostic factors in patients with surgically resected stages I and II non-small cell lung cancer. Ann Thorac Surg, 70, 1168-71.

Khuhaprema T, Srivatanakul P, Sriplung H, et al (2007) Cancer in Thailand Volume IV, 1998-2000. Bangkok: National Cancer Institute, Thailand.

Khuhaprema T, Srivatanakul P, Attasara P, et al (2010) Cancer in Thailand Volume V, 2001-2003. Bangkok: National Cancer Institute, Thailand.

Khuhaprema T, Attasara P, Sriplung H, et al (2012) Cancer in Thailand Volume VI, 2004-2006. Bangkok: National Cancer Institute, Thailand.

Kleinbaum DG, Klein M (2005). Survival analysis: A selflearning text. Springer New York, Available: https://doi. org/10.1007/0-387-29150-4, Accessed 18 April 2017.

León-Atance P, Moreno-Mata N, González-Aragoneses F, et al (2011). Multicenter analysis of survival and prognostic factors in pathologic stage I non-small-cell lung cancer according to the new 2009 TNM classification. Arch Bronconeumol, 47, 441-6.

Li J, Zhu H, Sun L, Xu W, Wang X (2019). Prognostic value of site-specific metastases in lung cancer: A population based study. J Cancer, 10, 3079-86.

Lou Y, Dholaria B, Soyano A, et at (2018). Survival trends among non-small-cell lung cancer patients over a decade: impact of initial therapy at academic centers. Cancer Med, 7, 4932-42.

Micheli A, Ciampichini R, Oberaigner W, et al (2009) The advantage of women in cancer survival: an analysis of EUROCARE-4 data. Eur J Cancer, 45, 1017-27.

National Health Office (NHSO), Thailand. Available: https:// www.nhso.go.th/, Accessed 7 March 2017.

National Statistical Office Thailand (NSO). Available: http:// web.nso.go.th[Accessed on 7 March 2017.

Sagerup CM, Småstuen M, Johannesen TB, Helland $\AA$, Brustugun OT (2011). Sex-specific trends in lung cancer incidence and survival: a population study of 40,118 cases. Thorax, 66, 301-7.

Santong C, Sriplung H, Phunmanee A, Pattanittum P (2018). Trends and projections of lung cancer incidence in Khon Kaen province. Srinagarind Med J, 33, 222-8.

Schottenfeld D, Fraumeni JF (2006). Cancer epidemiology and prevention, third edition. Oxford University Press.

Sculier JP, Chansky K, Crowley JJ, et al (2008). The impact of additional prognostic factors on survival and their relationship with the anatomical extent of disease expressed by the 6th Edition of the TNM Classification of Malignant Tumors and the proposals for the $7^{\text {th }}$ Edition. $J$ Thorac Oncol, 3, 457-66.

SEER (2015) Surveillance, Epidemiology, and End Results Program, National Cancer Institute, DCCPS, SEER Stat Database: Incidence- SEER 9 Regs Research Data, Nov 2014 Sub (1973- 2012) Available: https://seer.cancer.gov, Accessed 18 April 2017.

Sriamporn S, Black RJ, Sankaranarayanan R, et al (1995). Cancer survival in Khon Kaen Province, Thailand. Int $J$ Cancer, 61, 296-300.

Sriplung H, Sontipong S, Martin N, et al (2003). Cancer in Thailand Vol. III, 1995-1997. Bangkok: National Cancer Institute.
Lung Cancer Survival, Cancer Registry, Targeted Therapy

Srisam-Ang K, Podhipak A, Narksawat K, Supaattagorn P, Tipayamongkholgul M (2005). Survival of patients with advanced non-small-cell lung cancer at Ubon Ratchathani Cancer Center, Thailand. Southeast Asian J Trop Med Public Health, 36, 994-1006.

StataCorp (2007). Stata Statistical Software: Release 10. Texas, USA: StataCorp LP. Available: http://www.stata.com, Accessed 18 April 2017.

Suwanrungruang K, Vatanasapt P, Kamsa-Ard S, Sriamporn S, Wiangnon S (2011). Cancer survival in Khon Kaen, Thailand. IARC Sci Publ, 162, 211-6.

Sukauichai S, Tovanabutra C, Wanglikitkul S, Chomprasert k (2018). Survival of patients with advanced NSCLC treated with first-generation EGFRTKIs at a cancer hospital in Thailand, 2011-2016. J Med Oncl Ther, 3, 23-31.

Van Meerbeeck J, Galdermans D, Bustin F, et al (2014). Survival outcomes in patients with advanced non-small cell lung cancer treated with erlotinib: expanded access programme data from Belgium (the TRUST study). Eur J Cancer Care, 23, 370-9.

World Health Organization (2013). International classification of diseases for oncology (ICD-O)-3rd edition, 1st revision, Available: https://apps.who.int/iris/handle/ 10665/96612, Accessed 12 March 2018.

Xiaochuan L, Jiangyong Y, Ping Z, Xiaonan W, Lin L (2020). Clinical characteristics and prognosis of pulmonary large cell carcinoma: A population-based retrospective study using SEER data. Thorac Cancer, 11, 1522-32.

Zaitsu M, Toyokawa S, Tonooka A, et al (2015). Sex differences in bladder cancer pathology and survival: analysis of a population-based cancer registry. Cancer Med, 4, 363-70.

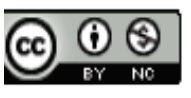

This work is licensed under a Creative Commons AttributionNon Commercial 4.0 International License. 